\title{
LOCALITIES OF INSECTS COLLECTED BY CHARLES ROBERTSON
}

\author{
By Charles Robertson, \\ Carlinville, Illinois.
}

References to my collections, observations and descriptions of insects relate to Carlinville, Illinois, and to Inverness and Orlando, Florida. Exceptions are some Oxybelidæ and 5 bees, Parandrena wellesleyana, Macropis morsei, Panurgus nove-anglio, Sphecodes davisii and Halictus hartii. The last, Hart's number 17211 , is the only Illinois bee in my descriptions which was not taken by me at Carlinville. "Southern", "South," "So.", "S.", "Macoupin County," and "Illinois" mean Carlinville. Some specimens marked "S. Illinois" were credited to "Illinois," the authors regarding that as sufficient.

Likewise, "Southern," "So.," and "S." Florida mean Inverness or Orlando. The "S. Florida" on my labels meant South Florida, which is not the same as Southern Florida.

Specimens numbered on white slips were taken on flowers by me at Carlinville. Of those numbered on red slips, 3346-3503 and 7021-7043 were taken at Orlando, Feb. and Mar., 1887, 1888 , all the rest at Inverness. Some specimens sent for determination did not have my regular numbers, but 1-11 et.c. 

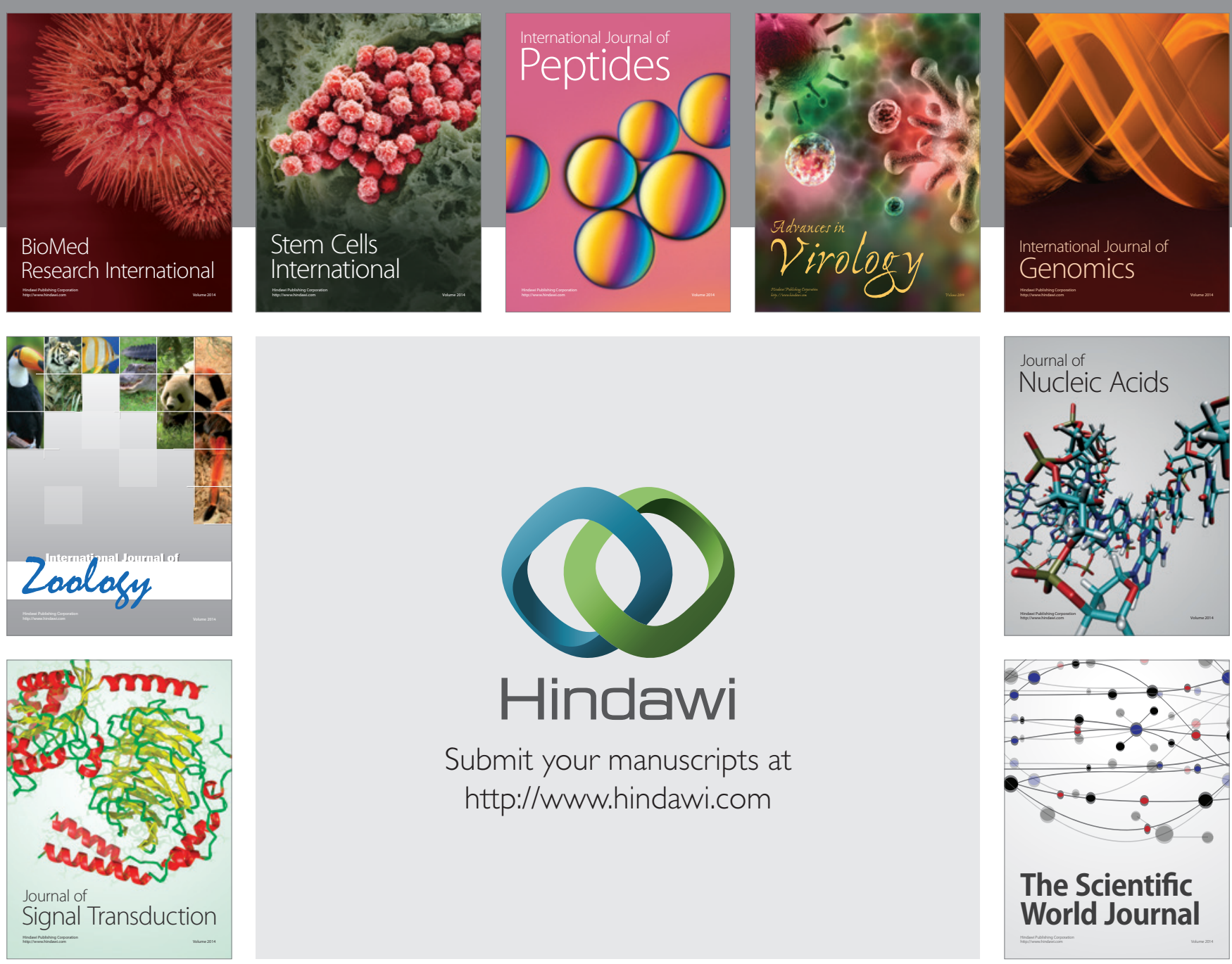

Submit your manuscripts at

http://www.hindawi.com
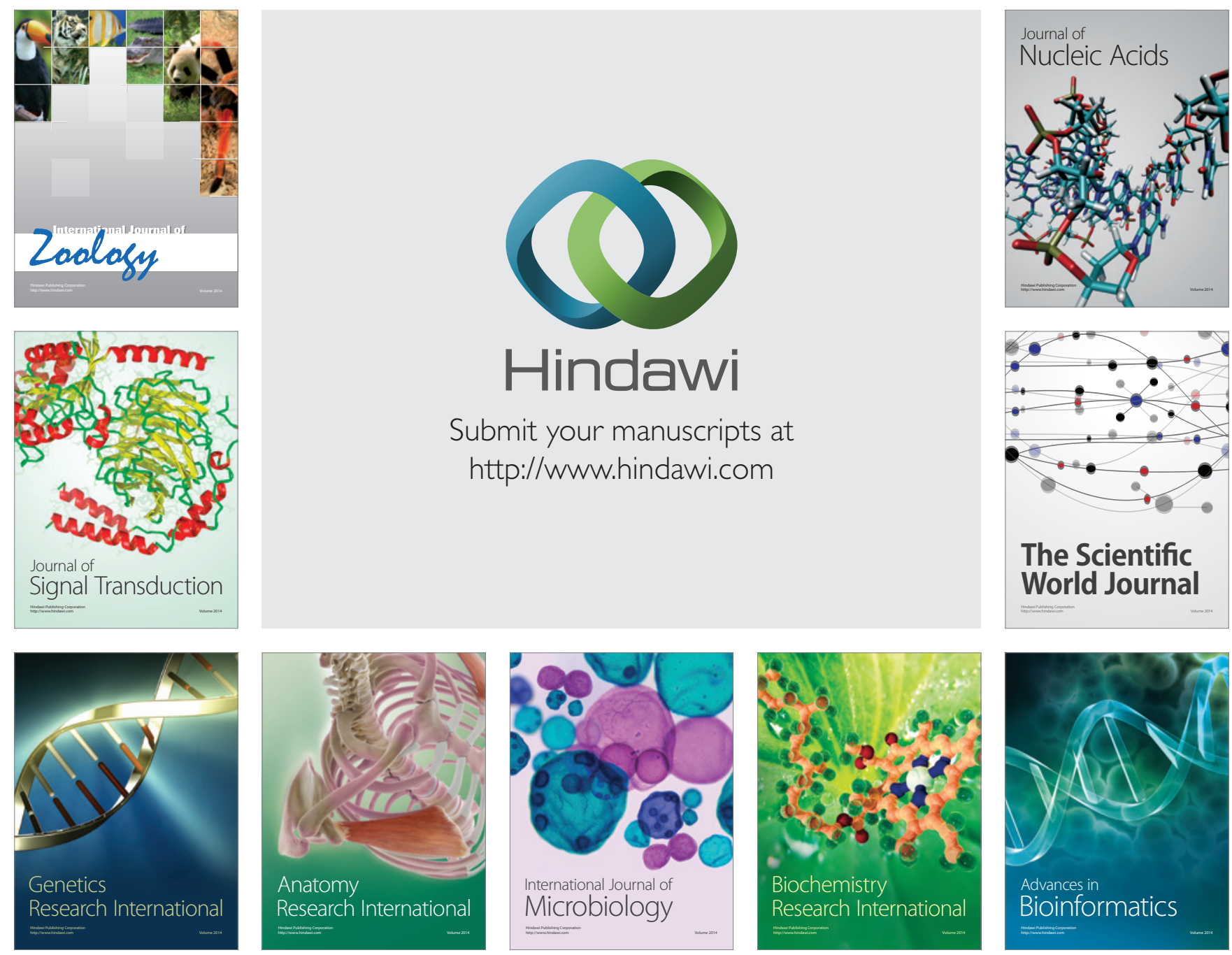

The Scientific World Journal
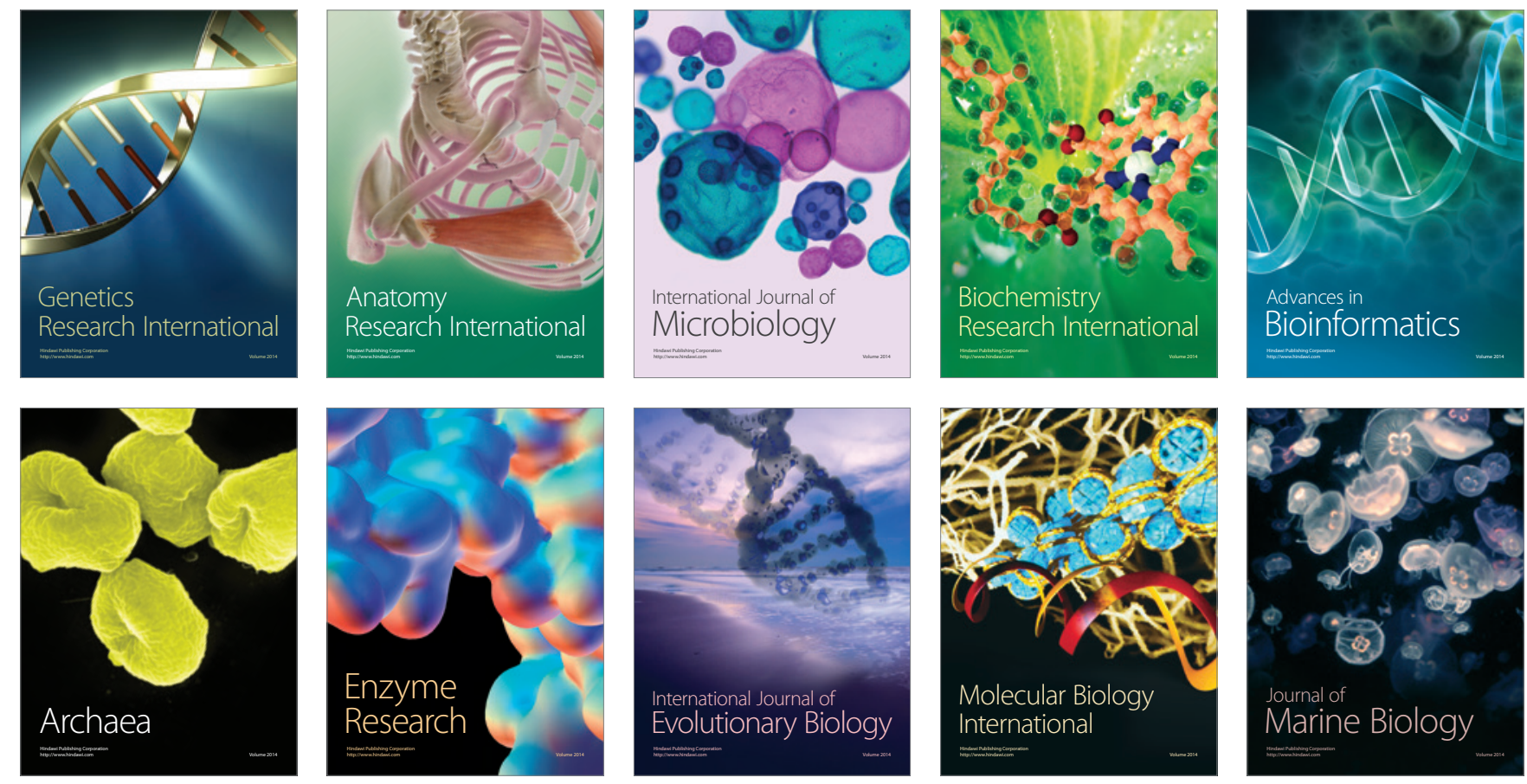